\title{
A study on the relationship between musical ability and EFL pronunciation proficiency
}

\author{
Mariola Kaszycka \\ John Paul II Catholic University of Lublin, Poland
}

\begin{abstract}
This study investigates the relationship between musical ability and pronunciation proficiency of English as a foreign language [EFL] of university students of English philology. English pronunciation of the participants is evaluated by academic teachers of English in three categories: the general impression of the foreign or native accent, the accuracy of production of English sounds and the use of word stress and intonation. This experiment was conducted entirely online. Participants' musical ability was tested using Gordon's Advanced Measure of Music Audiation [AMMA]. The results of this study demonstrate a moderately positive correlation between musicality and FL pronunciation proficiency. The more musical students, the higher marks from the judges. The present findings seem to be consistent with other studies which suggest that musical skills may positively affect the acquisition of foreign language pronunciation.
\end{abstract}

Keywords: musical ability, musicality, FL pronunciation, AMMA, pronunciation proficiency

\section{Introduction}

Foreign learners of English have numerous pronunciation difficulties which often make them unintelligible to native English speakers and cause serious communication problems (SzpyraKozłowska 2012). A considerable number of studies tend to suggest that foreign learners of English, including Polish ones, tend to make different kinds of pronunciation errors. The main source of these errors is a negative transfer from first language [L1] to the second language [L2] due to the differences between L1 and L2 sounds systems. According to Rojczyk (2015), the notion of transfer in foreign language accent imitation is the most crucial. As explained by Balas (2018: 16), "non-native speech sounds are incorrectly interpreted, because they pass through the filter of native phonology" which means that, without specific knowledge, an L2 learner does not distinguish some similar L2 and L1 sounds and categorises them as identical instead.

The pronunciation difficulties concern both segmental and supra-segmental features. In fact, EFL proficiency is affected by several factors, such as the age of the onset of L2 learning, personality, learning strategies, memory, prior experience, the similarity of the phonemic 
systems between the mother tongue and the target language and motivation (Milovanov et al. 2010: 56).

The role of musicality in foreign language acquisition and proficiency has always been noted as worth-investigating and it has recently been gaining greater attention. Throughout this paper, the term musicality will refer to musical ability in a broad sense, including an ear for music, musical talent or musical expertise and all these terms will be used interchangeably. Music and language share a considerable number of characteristics. Firstly, music and language are both perceived through the auditory system. Both music and language can be correlated on the basis of the same acoustic parameters, such as intensity, duration, frequency or timbre (Chobert and Besson 2013: 924). Secondly, in both cases sound production is involved. According to Patel (2012: 8), several studies showed a strong link between musical ability and 'linguistic phonemic abilities'. The acquisition of both music and language requires several other cognitive capacities, such as memory ability to store words in language and, analogously, melodies in music. Unlike any other human domain, both music and language call for vocal production, imitation, as well as control of sound expression. Music and language are also relatively important in the social context. It is necessary to emphasise that this area of research is being in constant development and a number of studies investigating the relationship between music and language is ever increasing. According to a number of parallels between music and language, in recent years, many researchers have started to investigate the influence of musical ability on foreign language pronunciation proficiency. Several studies (Baills et al. 2021; Pai et al. 2016; Christiner and Reteirer. 2013; Christiner and Reteirer 2015; Milovanov et al. 2010; Schön et al. 2004; Besson et al. 2006; Slevc and Miyake 2006; Gralińska-Brawata and Rybińska 2017; Połać 2014; Pastuszek-Lipińska 2008, Chang 2015) confirmed some positive effect of musical ability on FL pronunciation expertise. The present study was a preliminary investigation of examining the role of musical capacity in EFL pronunciation proficiency in first-year English philology majors. The results show to what extent musicality may influence FL pronunciation proficiency and which areas of pronunciation are the most correlated with musicality.

\section{EFL pronunciation}

One of the reasons why English pronunciation causes so many problems to the learners, including Polish learners is that very little attention tends to be paid to teaching pronunciation in English classroom. Teachers concentrate on drilling vocabulary and grammar, focusing on fluency rather than accuracy (Waniek-Klimczak 2015: 76), whereas foreign language pronunciation is one of the most difficult aspects to acquire (Fraser 2000: 7-8). Trask (1996: 291) defines pronunciation as "the manner in which speech sounds, especially connected sequences are articulated by individual speakers or by speakers generally." Speaking involves many sub-skills, out of which pronunciation is the most important one because "with good pronunciation, a speaker is intelligible despite other errors; with poor pronunciation, a speaker can be very difficult to understand, despite accuracy in other areas. Pronunciation is the aspect that most affects how the speaker is judged by others, and how they are formally assessed in 
other skills" (Fraser 2000: 7). Although pronunciation is so important, it is still an aspect on which least time is spent in EFL courses (Waniek-Klimczak 2015).

Szpyra-Kozłowska (2012: 243) makes an extensive list of errors in foreign-accented English, including Polish English. These errors “significantly decrease Polish learners' comprehensibility and intelligibility, create the impression of a heavy foreign accent and are irritating for native English listeners." However, correct pronunciation is a real challenge in L2 learning. Acquiring native-like pronunciation is virtually impossible and there are certain aspects that learners follow in order to achieve a near-native proficiency in FL pronunciation. Sobkowiak (2008) provides a list of common pronunciation errors made by Polish learners of English. These include final devoicing, vowel length, place and manner of articulation, connected speech, word-stress and intonation. Interestingly, these errors are observed at all levels of proficiency. Even advanced English majors encounter some difficulties speaking English and, as a result, they often speak with a heavy foreign accent. Veenendaal et al. (2016: 2-3) state that phonological awareness is the ability to separate sound units in speech and this ability refers to supra-segmental phonology. This includes "awareness of speech rhythm, and perception and production of stress placement and word boundaries." Poorly developed phonological awareness may result in difficulties in foreign language pronunciation because if a learner is not able to perceive the sound correctly, he or she may not be able to produce it accurately or correct himself. As suggested by Peynircioglu (2002: 69), this phonological awareness may be "a general ability for auditory pattern recognition" similar to that which is responsible for discriminating components of music.

\section{Music and language}

Music and language are two main channels of communication, both perceived through the auditory system (Jackendoff 2009: 195-197). Both music and language can be correlated on the basis of the same acoustic parameters, such as intensity, duration, frequency or timbre (Chobert and Besson 2013: 924). In both cases sound production is involved. According to Patel (2012: 8), several studies showed a strong link between musical ability and phonemic abilities (phonological awareness). Moreover, the acquisition of both music and language requires several other cognitive capacities, such as memory ability to store words in language and, analogously, melodies in music. Interestingly, unlike any other human domain, both music and language call for vocal production, imitation and control of sound expression. From the more generative perspective, similarly to language, music "uses rule-governed combinations of a limited number of elements to generate an unlimited number of hierarchically structured signals" (Fenk-Oczlon and Fenk 2009: 2).

According to all those parallels between music and language, in recent years, many researchers started to investigate the relationship between these two domains in several different aspects, including the impact of musicality on FL pronunciation proficiency. A considerable number of studies confirmed certain positive effects of musical ability on speech perception. The ability to perceive speech and correctly discriminate its prosodic changes can significantly enhance further FL proficiency. One of the possible effects is pitch processing, as observed in Schön et al. (2004) and Besson et al. (2007). The positive influence of musical 
experience on speech perception is also seen in studies conducted by Chang et al. (2015), in which musicians outperformed non-musicians on tonal discrimination of speech. Several studies concentrated on determining to what extent musical capacity facilitates phonological awareness. An experiment conducted by Degé et al. (2015) proved that skills not achieved through an intentionally arranged musical training, but rather musical potentials, can notably influence phonological awareness abilities. A number of researchers, including Polish, (Pai et al. 2016; Christiner and Reteirer 2013; Christiner and Reteirer 2015, Milovanov et al. 2010; Slevc and Miyake 2006; Gralińska-Brawata and Rybinska 2017; Połać 2014; Pastuszek-Lipińska 2008) decided to investigate whether musical ability can improve FL pronunciation. The results showed that participants with high musical aptitude outperformed those of low musicality in such tasks as speech and accent imitation, word stress or intonation. Arjomad (2015), Moreno and Besson (2006), François and Schön (2011) or Chobert et al. (2012), investigated the role of musical training in FL speech production. On the basis of the results, it seems that musical ability, in a broad sense, may have positive influence in acquiring correct and native-like FL pronunciation. Overall, these studies highlight the need for examining the relationship between musicality and FL pronunciation.

In the view of the above, the present study aims at investigating the correlation between musical ability and EFL pronunciation proficiency. This study therefore seeks to examine to what extent musical ability may affect FL pronunciation and which aspect of pronunciation is mostly correlated with musicality. According to the findings of the previous studies, the key research question of this paper is whether or not FL pronunciation proficiency is correlated with musical ability. Another question is whether the influence of musical ability on FL pronunciation proficiency is different for segmental and supra-segmental features.

\section{Methodology}

The study was conducted entirely in an online form. In most recent production-based studies, such as Coumel et al. (2019), Slevc and Milyake (2006), Połać (2014) or Arjomad (2006), the relationship between musicality and FL pronunciation was usually investigated by recording students talking or reading the stimuli and subsequently, evaluating their performances by native speakers of the target language. In the present study, native English speakers were not used as raters. Instead, a group of Polish academic teachers of English, including English pronunciation teachers, were asked to evaluate student's pronunciation.

\subsection{Participants}

Nineteen participants (11 females, 8 males) of age between 19 and 23 (Mean $(M)=20.3$, Standard Deviation $(S D)=1.20$ ) were recruited from the first and second year of English philology course at the John Paul II Catholic University of Lublin. They were not paid for the participation. All of them were native speakers of Polish apart from one girl who was a native speaker of Ukrainian. The first year students had undergone one and half a semester of an advanced English course (including an intensive phonetic training) and the second year students had undergone more than three semesters of the advanced English course. 


\subsection{Stimuli}

The stimuli comprised a short dialogue 'Will you watch Sheila for me' taken from Mortimer (1975: 48). The form of a dialogue read by one person was chosen in order to obtain as much natural performances as possible, yet still in a controlled environment. This form involved participants in a kind of acting, which also required some use of melody (word stress and intonation), besides focusing on segmental features.

\subsection{Procedure}

\subsubsection{Dialogue recordings and pronunciation assessment}

Although the students were not allowed to practise the dialogue before recording it, they were asked to read it once or twice in order to get familiar with it. Subsequently, they were instructed how to record themselves using their mobile phones or computers. The recordings were sent as m4a files via e-mails.

Each recording was then uploaded to questionpro.com, a website where an online questionnaire was created. Three questions were attached to each recording: The first question, 'What is your general impression on this student's pronunciation?' intended to determine to what extent a student speaks with a heavy foreign accent in general. In the second question, 'How do you evaluate this student's pronunciation of English sounds?' the raters were asked to judge whether a participant pronounces English sounds correctly or rather mistakes them for L1 or other sounds. The last question, 'How do you evaluate student's melody?' intended to assess student's use of word stress and intonation. All three questions were to be answered using a five point Likert scale, where 1 was 'a strong foreign accent' and 5 was 'near-native production'. The raters were given a written instruction what exactly they were supposed to judge.

A jury of twelve Polish university teachers of English at The John Paul II Catholic University of Lublin were sent links to the online questionnaire. All raters were native speakers of Polish and they teach English pronunciation to English philology majors. Their teaching experienced ranged between 8 and 22 years.

\subsubsection{Musicality assessment and surveys}

Participant's musicality was tested using an online musicality tests - Gordon's Advanced measure of Music Audiation [AMMA]. Students were sent links and short instructions to the test. This perception-based task consists of 30 pairs of melodies (musical statement followed by a musical answer). Students 'role was to listen to each pair of melodies and decide whether they sound the same or different. If students decided that the musical statement is different than the musical answer, they had to decide whether they are different rhythmically or tonally. The participants could also answer 'I don't know'. On average the AMMA test lasted 15-20 minutes. 
At the end, the participants were sent short surveys in which they answered questions about their age, sex, year of studies, musical education, musical abilities and the amount of English input and their exposure to English. The surveys were sent via email to the participants in .docx format. On average filling the survey lasted up to five minutes.

\subsection{Results}

\subsubsection{Musicality}

The results of AMMA are compared using a percentile marking for tonal scores, rhythm scores and both combined together. In the present study no distinction between tonal and rhythm scores was taken into consideration. Instead, the participants' musicality was determined by comparing tonal and rhythm scores combined together. The participants' combined percentile scores were the average $(\mathrm{M}=55.73, \mathrm{SD}=23.49)$.

\subsubsection{Musicality and general impression}

The mean score for general impression of students' pronunciation on the five-point scale was $\mathrm{M}=2.60, \mathrm{SD}=0.62$. These points were compared to the percentile score they obtained in the musicality test. Pearson's correlation coefficient was used to measure the relationship between the variables. A moderately positive correlation (Correlation coefficient $(R)=0.53$, Correlation of determination $(\mathrm{R} 2)=0.28$ ) was found between musical ability and general impression scores.

\subsubsection{Musicality and English sounds}

The mean score for English sounds evaluation on the five-point scale was $\mathrm{M}=2.51, \mathrm{SD}=0.56$. Musical ability and English sounds production were found to be moderately positively correlated $(\mathrm{R}=0.51, \mathrm{R} 2=0.26)$.

\subsubsection{Musicality and melody}

The mean for the melody assessment on the five-point scale was $\mathrm{M}=2.41, \mathrm{SD}=0.68$. A moderately positive correlation $(\mathrm{R}=0.63, \mathrm{R} 2=0.40)$ was found between musical ability and general impression scores.

\subsubsection{Musicality and total pronunciation score}

The mean score for the three aspects (general impression, English sounds and melody) altogether on Likert scale was $\mathrm{M}=2.51, \mathrm{SD}=0.58$. Musical ability and total pronunciation scores were found to be moderately positively correlated $(\mathrm{R}=0.59, \mathrm{R} 2=0.35)$, as can be seen in Figure 1 : 
5

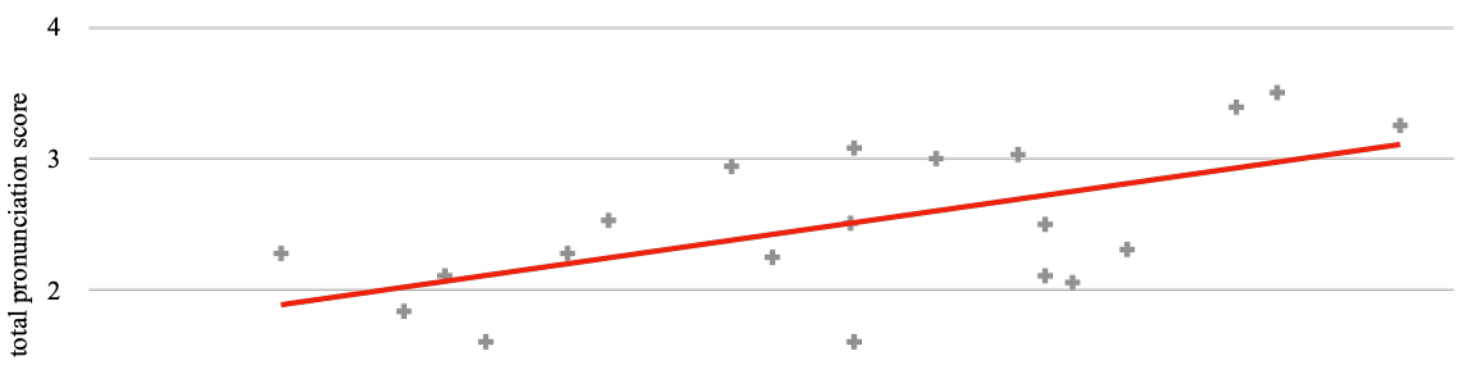

1

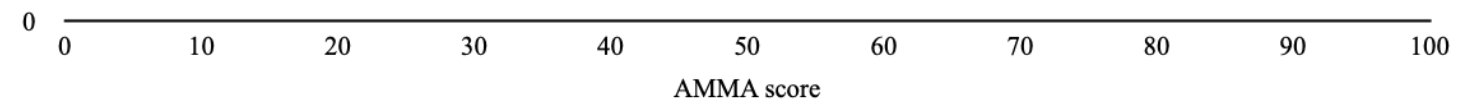

Figure 1: Musicality and total pronunciation score

\subsubsection{Surveys}

Of the study population, sixteen subjects completed and returned the surveys, eight of whom declared having some musical education or musical abilities. When the participants were asked to respond to a statement 'I have an ear for music' using a five-point scale (where 1 was 'I strongly disagree' and 5 was 'I strongly agree'), most of them $(\mathrm{M}=3.12, \mathrm{SD}=0.93)$ assessed their musical perception skills as rather good. On the same scale, subjects were asked to agree or disagree with a statement that their English pronunciation is very good. Most of them $(M=3.38$, $\mathrm{SD}=0.93$ ) agreed with the statement. The last statement of the survey was 'I think musical ability is correlated and positively influences FL pronunciation'. Interestingly, most of the students $(\mathrm{M}=3.48, \mathrm{SD}=1.17)$ also agreed with this statement. As not all of the students completed the surveys, this information was not correlated to their rating.

\section{Discussion}

The aim of this study was to investigate the correlation between musical ability and FL pronunciation proficiency. The findings of the present research clearly support the results of a number of previous studies (Pai et al. 2016; Christiner and Reteirer 2013; Christiner and Reteirer 2015; Milovanov et al. 2010; Slevc and Miyake 2006; Gralińska-Brawata and Rybińska 2017; Połać 2014; Pastuszek-Lipińska 2008) which showed that participants with higher musical aptitude usually outperformed those of lower musicality. As melody scored the lowest in the ranking, the most positive correlation was found between musicality and melody $(\mathrm{R}=0.63$, $\mathrm{R} 2=0.40$ ) which can be explained by a number of prosodic features of language such as intonation, rhythm, tone and timbre. The ability to perceive speech and correctly discriminate its prosodic changes can significantly enhance further FL proficiency. One of the possible effects is pitch processing, as observed in Schön et al. (2004) and Besson et al. (2006). The positive influence of musical experience on speech perception is also seen in studies conducted by 
Chang et al. (2015), in which musicians outperformed non-musicians on tonal discrimination of speech. A similar result was found in a study conducted by Akiyoshi (2013), where students with higher musicality also outperformed students with lower musicality in intonation perception and production tasks.

All three aspects of English pronunciation were rated as mid values on the scale even though the participants were English philology students of the first and second year, who had already undergone at least one and half a semester of an advanced pronunciation course. Overall, their pronunciation was assessed as average $(\mathrm{M}=2.51, \mathrm{SD}=0.58)$. These findings seem to confirm the claim that even advanced EFL learners have many difficulties with English pronunciation (Sobkowiak 2008, Szpyra-Kozłowska 2011). Interestingly, in the surveys, the majority of the students assessed their English pronunciation as rather good $(M=3.38$, $\mathrm{SD}=0.93$ ). From this data, it can be also seen that among these three aspects, participants got the lowest marks for their use of melody. This seems to confirm an observation that intonation and other aspects of melody are very often ignored in teaching FL pronunciation (Gilakjani and Sabouri 2016; Lantolf 1976).

\section{Conclusions and further implications}

Returning to the hypothesis posed at the beginning of this paper, the results demonstrate a rather visible relationship between musical ability and FL pronunciation proficiency can be observed. Production scores compared in the general analysis evidenced that students who scored higher in the musicality test performed better in the whole experiment than those students of a lower musicality scores. The findings of this study have also some implications on pronunciation teaching and learning. It seems that musical ability or having an ear for music may enhance, to some extent, FL acquisition, including speech perception and production.

\section{Limitations}

The most important limitation lies in the fact that the COVID-19 pandemic surprisingly occurred which had changed the original design of the study into an entirely online experiment. In order to obtain more statistically reliable results, the investigation should involve greater number of participants. Students' musicality could be assessed not only using a perceptionbased test, but also a production task, such as imitation task. This was, however, not possible due to the lockdown. The quality of the dialogue recordings varied, nevertheless, obtaining recordings in .wav format ensured a rather high quality of the sound regarding the circumstances the recordings were made.

\section{References}

Akiyoshi, J. 2013. The relationship between musical ability and the perception and production of L2prosodic features. MA diss. Mankato, Minnesota State University.

Arjomad, M. 2015. The effect of listening to music on the pronunciation of lower intermediate Iranian EFL learners. International journal of Education and Research 3(4): 101-112. 
Baills, F., Zhang, Y., Cheng, Y., Bu, Y., and P. Prieto. 2021. Listening to songs and singing benefitted initial stages of second language pronunciation but not recall of word meaning. Language Learning 71(2): 369-413.

Balas, A. 2018. Non-native vowel perception. The interplay of categories and features. Poznan': Wydawnictwo Naukowe UAM.

Besson, M., Schön, D., Moreno, S., Santos, A., and C. Magne. 2007. Influence of musical expertise and musical training on pitch processing in music and speech. Restorative Neurology and Neuroscience 25(3-4): 399-410.

Chang, D., Hadberg, N., and Y. Wang. 2015. Effects of musical and linguistic experience on categorisation of lexical and melodic tones. The Journal of the Acoustical Society of America 139(5): 2432-2447.

Chobert, J., and M. Besson. 2013. Musical expertise and second language learning. Brain Sciences 3(4): 923-940.

Chobert, J., François, C., Velay, J., and M. Besson. 2012. Twelve months of active musical training in 8- to 10-yearold children enhances the preattentive processing of syllabic duration and Voice Onset Time. Cerebral cortex 24(4): 956-967.

Christiner, M., and S. M. Reiterer. 2013. Song and speech: Examining the link between singing talent and speech imitation ability. Frontiers in Psychology 4(874): 1-11.

Christiner, M., and S. M. Reiterer. 2015. A Mozart is not a Pavarotti: Singers outperform instrumentalists on foreign accent imitation. Frontiers in Human Neuroscience 9(482): 1-8.

Coumel, M., Christiner, M., and S. M. Reiterer. 2019. Second language accent faking ability depends on musical abilities, not on working memory. Frontiers in Psychology 10(257): 1-10.

Crystal, D. 2003. English as a global language. New York, NY: Cambridge University Press.

Degé, F., Kubicek, C., and G. Schwarzer. 2015. Associations between musical abilities and precursors of reading in preschool aged children. Frontiers in Psychology 6(1220): 1-10.

Fenk-Oczlon, G., and At. Fenk. 2009. Some parallels between language and music from a cognitive and evolutionary perspective. Musicae Scientiae 13(2): 1-26.

Firth, A. 1996. The discursive accomplishment of normality. On "lingua franca" English and conversation analysis. Journal of Pragmatics 26: 237-259.

François, C., and Schön, D. 2011. Musical expertise boosts implicit learning of both musical and linguistic structures. Cerebral Cortex 21(10): 2357-2365.

Fraser, N. 2000. Rethinking recognition. New Left Review 3: 107-118.

Gilakjani, P. A., and N. Sabouri. 2016. Why is English pronunciation ignored by EFL teachers in their classes?. International Journal of English Linguistics 6(6): 195-208.

Gralinska-Brawata, A., and P. Rybińska. 2017. The relationship between the production of word stress and musical abilities in Polish learners of English. Research in Language 15(3): 265-283.

Jackendoff, R. 2009. Parallels and nonparallels between language and music. Music Perception: An Interdisciplinary Journal, 26(3): 195-204.

Lantolf, J. P. 1976. On teaching intonation. The Modern Language Journal 60(5/6): 267-274.

Milovanov, R., Pietila, P., Tervaniemi, M., and P. A. A. Esquef. 2010. Foreign language pronunciation skills and musical aptitude: A study of Finnish adults with higher education. Learning and Individual Differences 20(1): $56-60$.

Moreno, S., and M. Besson. 2006. Musical training and language-related brain electrical activity in children. Psychophysiology 43(3): 287-291.

Mortimer, C. 1975. Sound right! Selected sounds in conversation. A course in English Phonetics. Harlow: Longman.

Pastuszek-Lipińska, B. 2008. Musicians outperform non-musicians in speech imitation. Computer music modelling and retrieval. Sense of Sounds: 4th International Symposium, CMMR 2007, 56-73.

Patel, A. D. 2012. Language, music, and the brain: a resource-sharing framework. In P. Rebuschat, M. Rohrmeier, J. Hawkins, and I. Cross (eds.), Language and music as cognitive systems, 204-223. Oxford: Oxford University Press.

Pei, Z., Wu, Y., Xiang, X., and H. Qian. 2016. The effects of musical aptitude and musical training on phonological production in foreign languages. English Language Teaching 9(6): 19-29.

Peynircioğlu A. A. 2002. Effects of bilingual and monolingual presentations and time on concept- and languagematching tasks. Psychological Reports 91(1): 17-27. 
Połać, A. 2014. Musical ability and its influence on foreign language pronunciation. In O. Majchrzak (ed.) PsychoLingwistyczne Ekploracje Jezykowe 3, 113-128. Wydawnictwo Uniwersytetu Łódzkiego.

Rojczyk, A. 2015. Using FL accent imitation in L1 in foreign-language speech research. In E. Waniek-Klimczak and M. Pawlak (eds.), Teaching and Researching the Pronunciation of English, Second Language Learning and Teaching, 223-233. Springer, Cham.

Schön, D., Magne, C., and M. Besson. 2004. The music of speech: Music training facilitates pitch processing in both music and language. Psychophysiology 41: 341-349.

Slevc, L. R., and A. Miyake. 2006. Individual differences in second-language proficiency: Does musical ability matter? Psychological Science 17(8): 675-681.

Sobkowiak, W. 2008. English phonetics for Poles. Poznań: Wydawnictwo Poznańskie.

Szpyra-Kozłowska, J. 2011. Phonetically difficult words in intermediate learners' English. In Pawlak, M,. E. Waniek-Klimczak and J. Majer (eds.). Speaking in contexts of instructed foreign language acquisition, 286299. Bristol: Multilingual Matters.

Szpyra-Kozłowska, J. 2012. Mispronounced lexical items in Polish English of advanced learners. Research in Language 10(2): 243-256.

Trask, R. 1996. A dictionary of phonetics and phonology. London: Routledge.

Veenendaal, N. J., Groen, M. A., and L. Verhoeven. 2016. The contribution of segmental and suprasegmental phonology to reading comprehension. Reading research quarterly 51(1): 55-66

Waniek-Klimczak, E. 2015. Correctness in pronunciation instruction: Teachers' and learners' views. Konin Language Studies 3(1): 75-88. 